\title{
Adsorption Studies of Chromium by Using Low Cost Adsorbents
}

\author{
N. Gandhi ${ }^{1 *}$, D. Sirisha ${ }^{1}$ and K.B. Chandra Sekhar ${ }^{2}$ \\ ${ }^{1}$ Centre for Environment and Climate Change, School of Environmental Sciences, Jawaharlal Nehru Institute of \\ Advanced Studies, Hyderabad, A.P. \\ ${ }^{2}$ Department of Chemistry, Jawaharlal Nehru Technological University Anantapur, A.P \\ *E-mail: gandhinenavath@yahoo.com
}

Received: 11.07.2012, Accepted: 13.05.2013

\begin{abstract}
The presence of toxic heavy metals such as chromium (VI) contaminants in aqueous streams, arising from the discharge of untreated metal containing effluents into water bodies, is one of the most important environmental problems. Adsorption is one of the effective techniques for chromium (VI) removal from wastewater. In the present study, adsorbent was prepared from low cost adsorbents and studies were carried out for chromium (VI) removal. Batch adsorption studies demonstrated that the adsorbents had significant capacity to adsorb the chromium from aqueous solution. It was found that the adsorption increased with increase in contact time and adsorbent dosage. An attempt was made to study mixed algae as an adsorbent for removal of chromium (VI).
\end{abstract}

Key words: Chromium, Adsorption, Multhani mitti, Batch adsorption, Mixed algae

\section{Introduction}

Water is the most vital element among the natural resources, and is crucial for the survival of all living organisms. The increasing urbanization and industrialization of Hyderabad have negative implications for water quality. The pollution from industrial and urban waste effluents and from agrochemicals in some water bodies and rivers has reached alarming levels. There are numerous ill effects of pollution, each type of pollutants having different effect, on human and animal health and ecology. Chromium is one of the water pollutants which is actually a micro nutrient required by our body in minute quantity. This form of chromium is the safe trivalent or 'Chromium-3'. Chromium also exists in another very rare form known as 'Hexavalent chromium' or 'Chromium-6'. Hexavalent chromium-6 is usually introduced into ground water when chemical industries using chromium, discharge their water without proper treatment. Hexavalent chromium-6 is poisonous and should be guarded against people using well water. It causes cancer, anuria, nephritis, gastrointestinal ulceration, perforation in partition of nose. It penetrates cell membrane and badly affects central nervous system, causes respiratory trouble, and lung tumors when inhaled. Trace amount of Cr III is essential for normal glucose, protein and fat metabolism and hence it is an essential trace element in diet. 
The accumulation of metals by algae has been extensively studied in the last two decades (APHA, 1992).

Chromium metal ions are usually removed by precipitation although ion exchange and adsorption are also used for its removal. The hydroxides of heavy metals are usually insoluble, so lime is commonly used for precipitating them. There are various methods to remove $\mathrm{Cr}$ (VI) including chemical precipitation, membrane process, ion exchange, liquid extraction and electrodialysis (Argun et al., 2007). These methods are non-economical and have many disadvantages such as incomplete metal removal, high reagent and energy requirements, generation of toxic sludge or other waste products that require disposal or treatment. In contrast, the adsorption technique is one of the preferred methods for removal of heavy metals because of its efficiency and low cost (Hasan et al., 2003). Utilizing the waste material from agriculture and industries can make treatment process economical and solve the solid waste disposal problem. The present study was aimed at selection of a low cost adsorbent, which can adsorb chromium from the wastewater.

\section{Materials and methods}

The adsorbents primarily screened were mangifera indica dust, horse gram powder, ragi powder, multhani mitti, brick powder, concrete, custard apple leaf and peel powder, chalk powder (Tab.1). Initially, all the adsorbents were screened by adding $1 \mathrm{~g}$ of each adsorbent to $100 \mathrm{ml}$ of solution of chromium.

Adsorption methods were adopted for removal of heavy metals and these methods are suitable when chromium is present in low concentrations. For this purpose, an aqueous solution of $100 \mathrm{ml}$ of chromium of various concentrations was taken in $100 \mathrm{ml}$ Stoppard bottles and $1 \mathrm{~g}$ of adsorbent was added to the solutions. Batch adsorption experiments were carried out at room temperature, a contact time of $24 \mathrm{~h}$ was maintained. The initial and final concentrations of aqueous solution of chromium were determined by colorimeter and percentage removal of chromium was determined (Gupta et al., 2003).

Table 1. Adsorbents and sampling sites.

\begin{tabular}{ll}
\hline Adsorbent & Sampling site \\
\hline Manjifera indica bark dust & Timber depots \\
Horse gram powder & Fields \\
Raghi powder & Fields \\
Multhani matti & Super market \\
Chalk powder & Class room \\
Brick powder & Construction site in \\
& Hyderabad city \\
Concrete & Construction site in \\
& Hyderabad city \\
Papaya peel powder & Fields \\
Papaya seed powder & Field \\
Mixed algae & Over head tank/ \\
& Water storage tank \\
\hline
\end{tabular}

\section{Preparation of $\mathrm{Cr}$ (VI) solution}

A stock solution of Cr (VI) $(0.35 \mathrm{~g} / 100 \mathrm{ml})$ was prepared by dissolving appropriate quantity of AR grade $\mathrm{K}_{2} \mathrm{Cr}_{2} \mathrm{O}_{7}$ in $100 \mathrm{ml}$ of distilled water from Millipore purification unit. The stock solution was further diluted with distilled water to desired concentration for obtaining the test solutions. The initial metal ion concentrations ranged from $10 \mu \mathrm{g}$ to $85 \mathrm{mg} / \mathrm{ml}$.

Final residual metal $\mathrm{Cr}$ (III) and $\mathrm{Cr}$ (VI) concentration after adsorption was directly measured with spectrophotometer. To estimate the percentage removal of chromium from aqueous solution the following equation was used: 
Removal of chromium

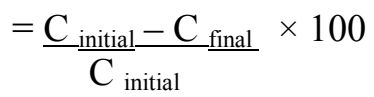

\section{Results and discussion}

The order of adsorption by different low cost material was Multhani matti > papaya seed powder $>$ mango bark dust $>$ mixed algae $>$ chalk powder $>$ papaya peel powder $>$ horse gram seed powder $>$ brick powder $>$ ragi seed powder $>$ concrete (Fig. 1). The adsorption capacity was more at lower concentrations than at higher concentrations.

Multhani mitti is known as montmorillonite and it contains grains of fine sand particle (Antunes et al., 2003; Hameed, 2009). Brick powder is the waste material from construction sites and it is used as the adsorbent. It has a high porosity and it is made from the local red mud from Hyderabad which has iron oxide, which forms chromium oxide. Chalk powder is the classrooms waste material. Chalk powder due to certain porosity adsorbs chromium from aqueous solution of chromium. Concrete material is a mixture of silica, stones and cement in the ratio of 1: 2:4. Mango bark dust was collected from a timber industry. It is most effective for the removal of chromium. Horse gram is a bio adsorbent for removal of chromium. Papaya peel is also a bio adsorbent responsible for chromium adsorption from aqueous solution. Ragi seeds are also responsible for chromium adsorption from aqueous solution. Mixed algae acts as a bio adsorbent for the removal of chromium. Papaya seeds acts as a bio adsorbent and effectively removes chromium from aqueous solution.

In most of adsorption processes commercially available, activated charcoals are used to study the adsorption. In the present study the adsorption found was very less because of less porosity and hardness of coal. Green algae, especially Cladophora species, are generally considered as the best bio indicator of aquatic bodies' contamination by nutrients as well as by heavy metals (Chmielewská-Horváthová, 1996). The role of algae in waste water treatment and their affinity for heavy metal cations, based on high negative surface charge, has been recognized for several decades. Taking all these factors into consideration mixed algae was selected as bio adsorbent. The batch adsorption studies were carried out with respect to contact time initial concentration of chromium and adsorbent dosage.

\section{Effect of contact time}

The initial and final concentrations were determined at regular intervals of time. The results are given in figure 2 .

Volume of chromium solution: $1000 \mathrm{ml}$ Amount of mixed algae biomass: $1.0 \mathrm{~g}$ Concentration of Cr: $85 \mathrm{mg} / \mathrm{lit}$

The study revealed that as contact time increases the percentage removal increases. It indicates that initially the adsorption process is directly proportional to contact time and it attains equilibrium in $5 \mathrm{~min}$ (Appel and Ma, 2002; Bose et al., 2002).

\section{Effect of concentration of chromium on algae}

Different concentrations of chromium were studied, which consisted of a fixed amount of adsorbent. The experiments were carried out with constant contact time and the contact time was fixed depending upon contact time experiments.

Volume of chromium solution: $100 \mathrm{ml}$ Mixed algae biomass: $1.0 \mathrm{~g}$ 
N. Gandhi, D. Sirisha and K.B. Chandra Sekhar / Our Nature (2013), 11(1): 11-16

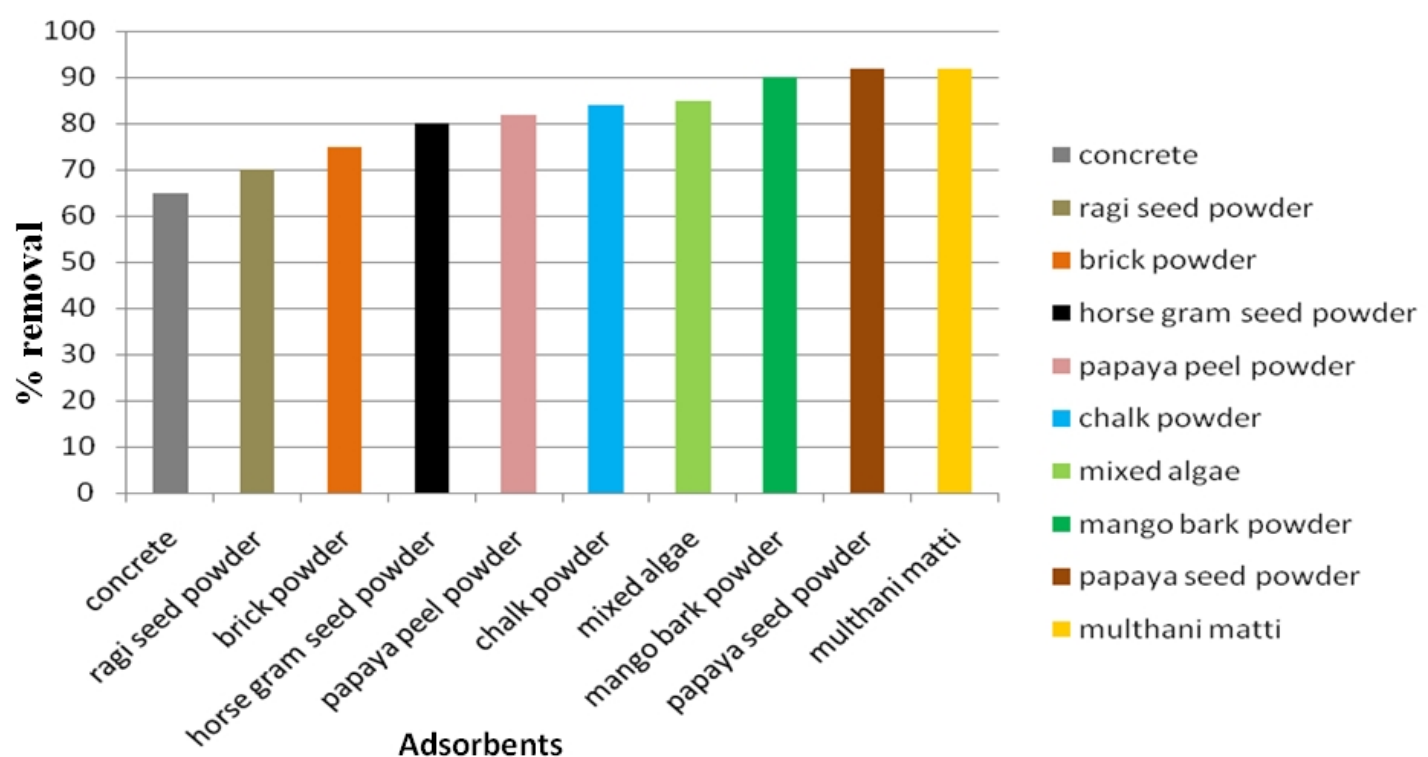

Figure 1. Order of effectiveness of adsorbents (Multhani matti $>$ papaya seed powder $>$ mango bark dust $>$ mixed algae $>$ chalk powder $>$ papaya peel powder $>$ horse gram seed powder $>$ brick powder $>$ ragi seed powder $>$ concrete).



Figure 2. Variation of contact time between chromium and mixed algae. 


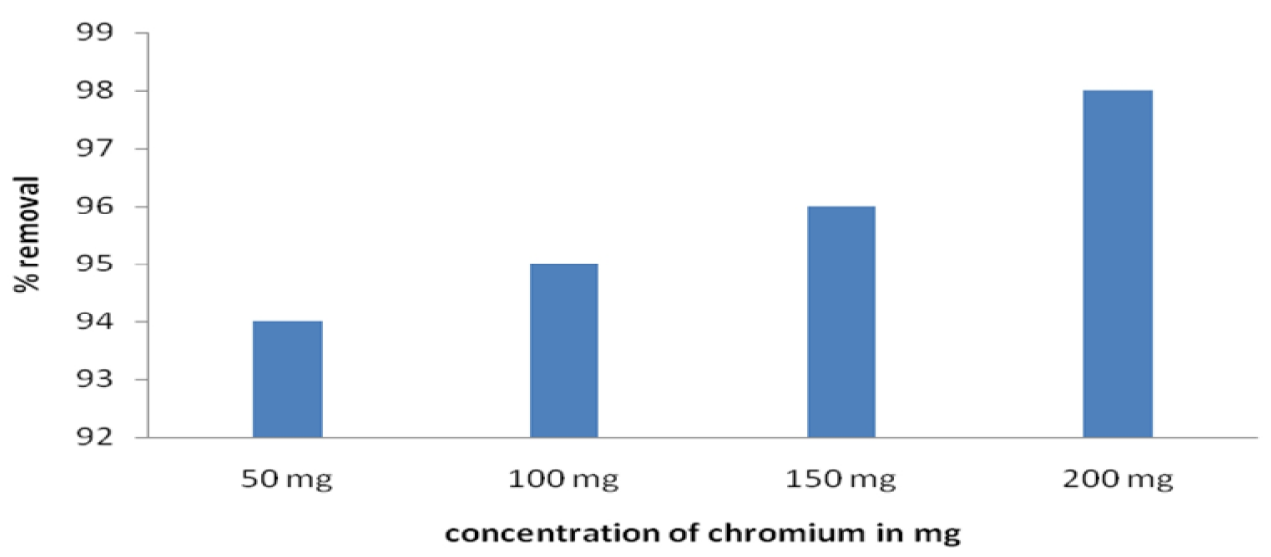

Figure 3. Variation of initial concentration of chromium.

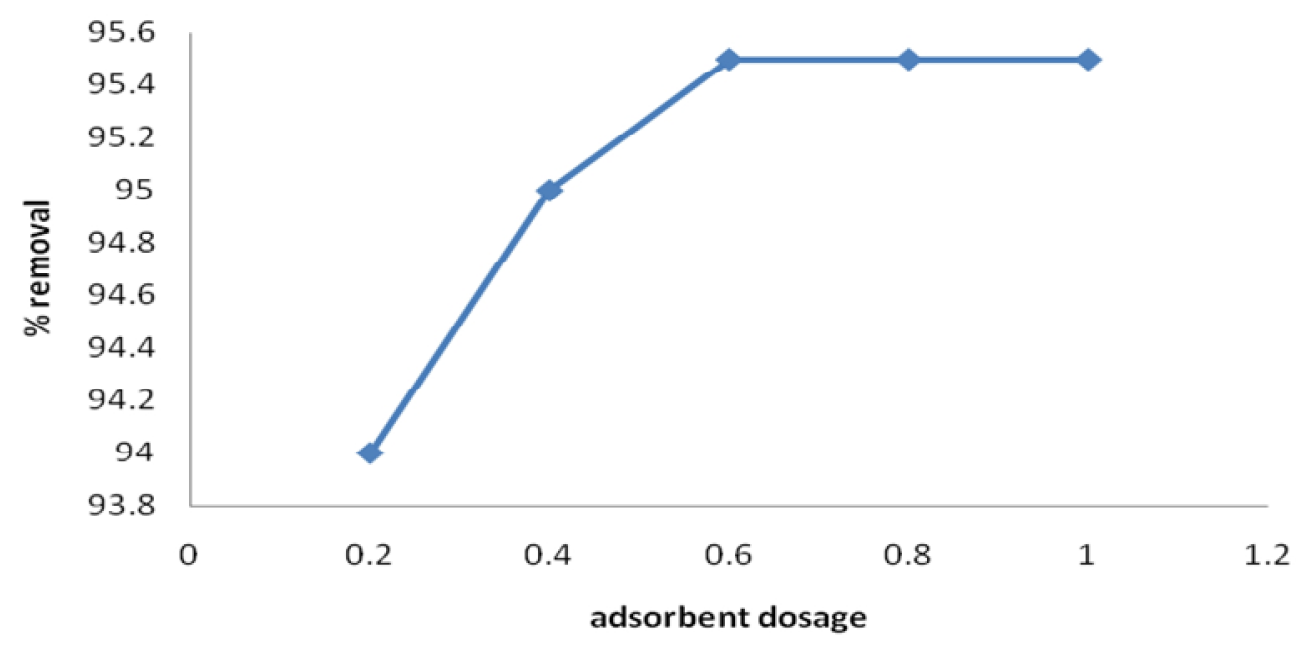

Figure 4. Variation of mixed algae dosages

The chromium removal efficiency is found to be increased with increase in chromium concentration (Fig. 3). The percentage removal of $\mathrm{Cr}$ is more and it is ranging between $93-98 \%$ for all concentrations (Orhan and Buyukgangor, 1993).

\section{Effect of algae dosages}

To study the effect of adsorbent dose (g) on the uptake of $\mathrm{Cr}$ (VI), experiments were done with $100 \mathrm{ml}$ of $85 \mathrm{mg}$ solutions, while the amount of adsorbent added was varied from $(0.2-0.8 \mathrm{~g})$. Results in figure 4 showed that the percentage removal of $\mathrm{Cr}(\mathrm{VI})$ from aqueous solution increased with the adsorbent dose and reached an optimum at $0.8 \mathrm{~g}$ of sorbent. The increase in ion removal was due to the increase in the available sorption surface area (Rafatullah et al., 2010) 


\section{Conclusions}

Among ten different adsorbents studied, Multhani mitti and Mango bark dust proved to be the most effective adsorbent of chromium from aqueous solution of chromium. Thus, our study proves that the effect of harmful metals like chromium can be reduced by using naturally available wastes and low cost materials like brick powder, Mango bark dust, mixed algae, Chalk powder, Ragi seed powder, horse gram seed powder, papaya seed powder, papaya peel powder, multhani mitti and Concrete. Among all the bio adsorbents mixed algae is widely available. Hence, this study provides an economic solution for cleaning up environmental water pollutant chromium and it is recommended to use these adsorbents in industries.

\section{Acknowledgements}

I would like to extend my sincere thanks and gratitude to Ch. Sujata Gangadhar, Registrar, Jawaharlal Nehru Institute of Advanced Studies for financial support.

\section{References}

Antunes, W.M., A.S. Luna, C.A. Henriques, A.C.A. Da Costa 2003. An evaluation of copper Biosorption by brown seaweed under optimized conditions. Electronic J. Biotech. 6(3): 174-184. APHA. 1992. Standard methods for the examination of water and wastewater. $18^{\text {th }}$ ed, APHA,
Washington, DC.

Appel, C. and L. Ma 2002. Heavy metals in the environment concentration, $\mathrm{pH}$ and surface charge effects on $\mathrm{Cd}$ and $\mathrm{Pb}$ sorption in three tropical soils. J. Environ. Qual. 21(3): 581-589.

Argun, M.E., S. Dursun, C. Ozdemir and M. Karatas 2007. Heavy metal adsorption by modified oak sawdust: thermodynamics and kinetics. J. Hazard. Mater. 141: 77-85.

Bose, P., M.A. Bose and S. Kumar 2002. Critical evaluation of treatment strategies involving adsorption and chelation for wastewater containing copper, zinc and cyanide. $A d v$. Environ. Res. 7(1): 179-195.

Chmielewská-Horváthová, E. $1996 . \quad$ Reverse equilibrium study for metal uptake on conditioned zeolite. Environment Prot. Eng. 22(3): 37-44.

Gupta, R.K., R.K. Naresh, P.R. Hobbs, J. Zheng and J.K. Ladha 2003. Sustainability of post-green revolution agriculture: the rice-wheat cropping systems of the Indo Gangetic Plains and China. In Improving the productivity and sustainability of rice-wheat systems: issues and impacts. pp. 1-25.

Hameed, B.H. 2009. Evaluation of papaya seeds as a novel nonconventional: low-cost adsorbent for removal of methylene blue. Journal of Hazardous Materials 162: 939-944.

Hasan, S., A. Krishnaiah, T.K. Ghosh, D.S. Viswanath, V.M. Boddu and E.D. Smith 2003. Adsorption of chromium (VI) on chitosan-coated perlite. Sep. Sci. Technol. 38: 3775-3793.

Orhan, Y. and H. Buyukgangor 1993. The removal of heavy metals by using agricultural wastes. Water Sci. Technol. 28: 247-255.

Rafatullah, M., O. Sulaiman, R. Hashim and A. Ahmad 2010. Adsorption of methylene blue on low-cost adsorbents. Journal of Hazardous Materials 177: 70-80. 